\title{
BMJ Open Characteristics and well-being of urban informal home care providers during COVID-19 pandemic: a population- based study
}

\author{
Emily YY Chan, ${ }^{1,2,3}$ Eugene SK Lo (D) , ${ }^{1,3}$ Zhe Huang (D) , , Jean H Kim, ${ }^{3}$ \\ Heidi Hung, ${ }^{1,3}$ Kevin KC Hung (1) , ${ }^{1,4}$ Eliza LY Wong (D) , ${ }^{3}$ Samuel YS Wong, ${ }^{3}$ \\ Nina Gobat ${ }^{5}$
}

To cite: Chan EYY, Lo ESK, Huang Z, et al. Characteristics and well-being of urban informal home care providers during COVID-19 pandemic: a populationbased study. BMJ Open 2020;10:e041191. doi:10.1136/ bmjopen-2020-041191

- Prepublication history and additional material for this paper is available online. To view these files, please visit the journal online (http://dx.doi.org/10. 1136/bmjopen-2020-041191).

Received 04 June 2020 Revised 07 October 2020 Accepted 16 October 2020
Check for updates

(C) Author(s) (or their employer(s)) 2020. Re-use permitted under CC BY-NC. No commercial re-use. See rights and permissions. Published by BMJ.

For numbered affiliations see end of article.

Correspondence to Professor Emily YY Chan; emily.chan@cuhk.edu.hk

\section{ABSTRACT}

Objectives Globally, the COVID-19 pandemic has overwhelmed many healthcare systems, which has hampered access to routine clinical care during lockdowns. Informal home care, care provided by nonhealthcare professionals, increases the community's healthcare capacity during pandemics. There is, however, limited research about the characteristics of informal home care providers and the challenges they face during such public health emergencies.

Design A random, cross-sectional, population-based, $\mathrm{RDD}$, telephone survey study was conducted to examine patterns of home care, characteristics of informal home care providers and the challenges experienced by these care providers during this pandemic.

Setting Data were collected from 22 March to 1 April 2020 in Hong Kong, China.

Participants A population representative study sample of Chinese-speaking adults $(n=765)$ was interviewed.

Primary and secondary outcome measures The study examined the characteristics of informal home care providers and self-reported health requirements of those who needed care. The study also examined providers' selfperceived knowledge to provide routine home care as well as COVID-19 risk reduction care. Respondents were asked of their mental health status related to COVID-19.

Results Of the respondents, $25.1 \%$ of 765 provided informal home care during the studied COVID-19 pandemic period. Among the informal home care providers, $18.4 \%$ of respondents took leave from school/ work during the epidemic to provide care for the sick, fragile elderly and small children. Care providers tended to be younger aged, female and housewives. Approximately half of care providers reported additional mental strain and $37.2 \%$ reported of challenges in daily living during epidemic. Although most informal home care providers felt competent to provide routine care, $49.5 \%$ felt inadequately prepared to cope with the additional health risks of COVID-19.

Conclusion During public health emergencies, heavy reliance on informal home healthcare providers necessitates better understanding of their specific needs and increased government services to support informal home care.

\section{Strengths and limitation of this study}

- This study was the first to highlight the impact and added burden of care experienced by informal home care providers among the general population, in a city affected in the early stages of the COVID-19 pandemic

- This computerized RDD telephone-based study was conducted during the peak period of COVID-19 epidemic, when citizens were encouraged to stay at home for work or daily activity.

- The cross-sectional design showed characteristics and patterns of informal care providers and recipients, but cause-effect relationship cannot be draw.

- The study results indicated that there were gaps in understandings of the needs of both imformal care providers and recipients.

\section{INTRODUCTION}

Home care is regarded as one of the major care models to address medical needs for patients and vulnerable populations during COVID-19 pandemic. $^{1}$ As described by the $\mathrm{WHO},{ }^{2}$ home care that provides high-quality and cost-effective care to individuals will enable the vulnerable to maintain their independence and the highest possible quality of life. While formal home care providers are usually remunerated workers from medical authorities or registered organisations, informal home care providers are usually family members or others who provide unpaid care to those in need. ${ }^{3}$ The typical profile of individuals who require home care are patients with chronic diseases or mental conditions, individuals with disabilities, young children, the elderly and other vulnerable individuals who live alone. Up to the present, the published literature has mainly examined the quality of life of older adults, the care recipients, the mental health of the 
care providers ${ }^{4-6}$ and experience of informal home care providers under non-emergency health situations. ${ }^{78}$

During the COVID-19 pandemic, in an attempt to reduce the surge of patients requiring hospital care, many countries have implemented epidemic control measures ${ }^{9}$ to limit activities outside the home such as closure of nonessential services. Moreover, countries have relied heavily on home quarantine for suspected COVID-19 patients with mild symptoms in order to maintain resilience of the national health system. ${ }^{1}{ }^{10}$ In Hong Kong, in conjunction with prohibitions on mass gatherings, closure of recreational centres, schools and community services, ${ }^{11} 12$ a mandatory 14 days quarantine was issued for those who entered into Hong Kong from outside its borders. ${ }^{13}$ This resulted in 13649 individuals under compulsory home quarantine from 13 March to 26 March 2020. ${ }^{14}$ In such a public health emergency, informal care may be the only care option for people in need. ${ }^{15}$ There have been no published studies of informal care providers during extreme events or during population-level health emergencies. Hence, the impacts on informal home care providers from the closure of community services and limited access to healthcare services during the COVID-19 are unknown.

According to the Hong Kong 2016 By-census, onefourth of households had children aged under 15 years, while one-third household reported having at least one elderly household member. ${ }^{16}$ Combined, these households were particularly in need of home care even in ordinary setting, accounting for $27.2 \%$ of the whole Hong Kong population. The likely heavy reliance on informal home care during a pandemic emergency in Hong Kong allows examination of the prevalence and special needs of informal home care providers. This study aimed to identify the pattern of informal home care, characteristics of informal home care providers and their challenges in Hong Kong during the COVID-19 epidemic. The study also seeks to examine the knowledge levels and level of preparation for the home quarantine among these care providers and the recipients of their care in Hong Kong.

\section{METHODS}

\section{Study design and study population}

A cross-sectional, population-based telephone survey was conducted from 22 March to 1 April 2020 during the peak of local COVID-19 pandemic. The computerised random digit dialling method was used for each of Hong Kong's 18 districts to randomly select a representative sample. The survey methods and the sample size estimation have been previously detailed ${ }^{17}$ Study tool was designed on the basis of literature review and previous research experience. ${ }^{18-21}$ The study only includes respondents who were 18 years old or older and spoke Cantonese.

\section{The study instruments}

A self-reported, semistructured Chinese questionnaire was used for data collection. ${ }^{17}$ The data collected included the subjects' perception, knowledge, preparedness and their home care experience, if available, of the COVID-19 during the pandemic. Since the home care recipients could include a wide range of different groups (eg, healthy children due to the closure of schools), care providers were identified through one of the questions in the questionnaire 'Do you currently need to look after member(s) of your family and relatives' daily needs (like your children/parents) during COVID-19 epidemic?'. Besides the experience and situations of their care duties during the COVID-19, the characteristics of the care recipients under their care were also investigated. Care recipients' age, sex, relationship with the care provider, the reason for the receiving care and their dependency were recorded. Care providers were also asked if they were the primary care providers for their recipients (defined as having the major responsibility in caregiving duties) and if their care recipient was dependent on them (defined as inability to maintain activities of daily living without care provider assistance). All self-reported home care providers in this study were confirmed to be informal care provider.

Care providers were asked if they felt that they possessed sufficient knowledge about routine care and COVID-19 risk mitigation. A 5-point Likert scale was used to assess physical, mental, social and other related health impact (ranging from $1=$ no impact to $5=$ =maximum impact). Respondents were asked about their home care experience, risks perception, household capacity to provide care and home care challenges that they experienced. The instrument also asked about knowledge of infection control during a home quarantine. Specifically, the respondents were asked about their knowledge of infection control in home context such as the ratio of bleach solution for cleaning (1:99 ratio for normal cleaning and 1:49 for cleaning vomit, excreta or secretion ${ }^{22}$ ) and the recommended distance from the quarantine subjects (at least $1 \mathrm{~m}^{22}$ ).

\section{Statistical analysis}

Descriptive statistics of the study sample were presented with $\chi^{2}$ tests to examine comparability of the study sample with the Hong Kong general census population. ${ }^{23}$ Sociodemographic pattern analyses of respondents who might have care-providing responsibilities, the home care recipients and the context of care provision during the COVID-19 were conducted. $\chi^{2}$ test was conducted for comparing the perception towards COVID-19 between care provider and non-care provider subjects. Multivariable logistic regression analysis was conducted to compare the sociodemographic predictors between care providers and non-care providers. In addition, logistic regression analysis was conducted to understand how the socio-demographic of the care providers and their care responsibilities may affect their daily living. For multivariable logistic regressions, the first step involved bivariate analyses $\left(\chi^{2}\right.$ test or independent t-test). Explanatory variables whose significance was $<0.10$ were entered as 
candidate variables into a multivariable logistic model. $\chi^{2}$ tests were then conducted between the care providers who believed they possess sufficient or insufficient knowledge in providing routine care and COVID-19 risk mitigation. Missing values will be excluded in the data analysis. No sensitivity analysis was conducted. The level of significance of statistical test was 0.05 . All statistical analyses were conducted using IBM SPSS V.21 for Windows. ${ }^{24}$

\section{Patient and public involvement}

The study design, data analysis, reporting, and dissemination of our research were done without patient or the public involvement.
RESULTS

Final study sample consisted of 765 respondents $(44.0 \%$ response rate) and was comparable with the population data in Hong Kong By-census 2016. Of the 765 participants, $53.5 \% \quad(\mathrm{n}=409)$ were women, $18.7 \% \quad(\mathrm{n}=143)$ were aged 65 years and above, and $60.2 \%(\mathrm{n}=459)$ were currently married. Information about the respondents and the recruitment process were detailed in a previous study in the same series. ${ }^{17}$

\section{Characteristics of the home care recipients $(n=345)$}

The study sample consisted of 192 care providers who reported of their needs to provide care for 345 care recipients. Among these home care recipients, children represented $55.2 \%$ (being taken care of by parents), parents and parent-in-law represented $21.4 \%$ (being taken care of by children and children-in-law), while spouses

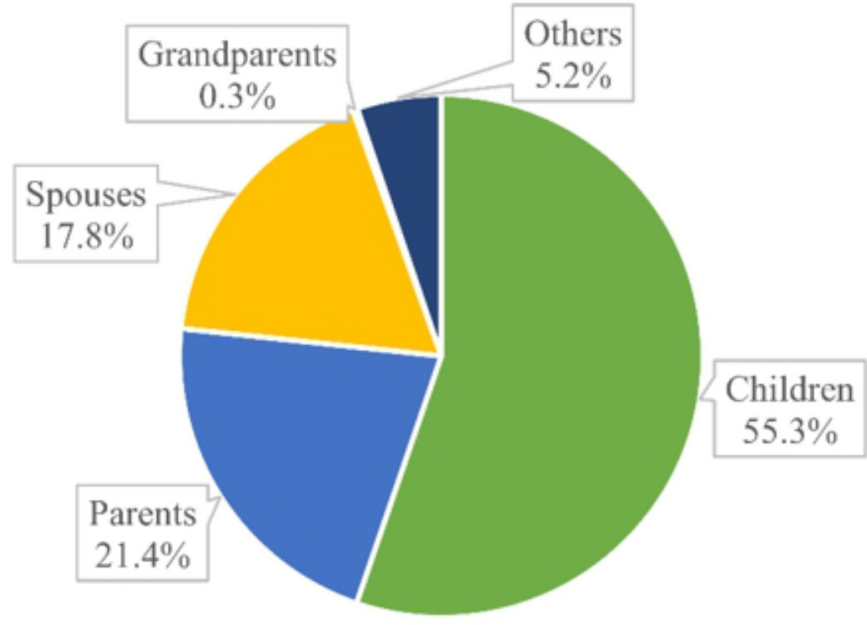

Fig. $1 \mathrm{a}$

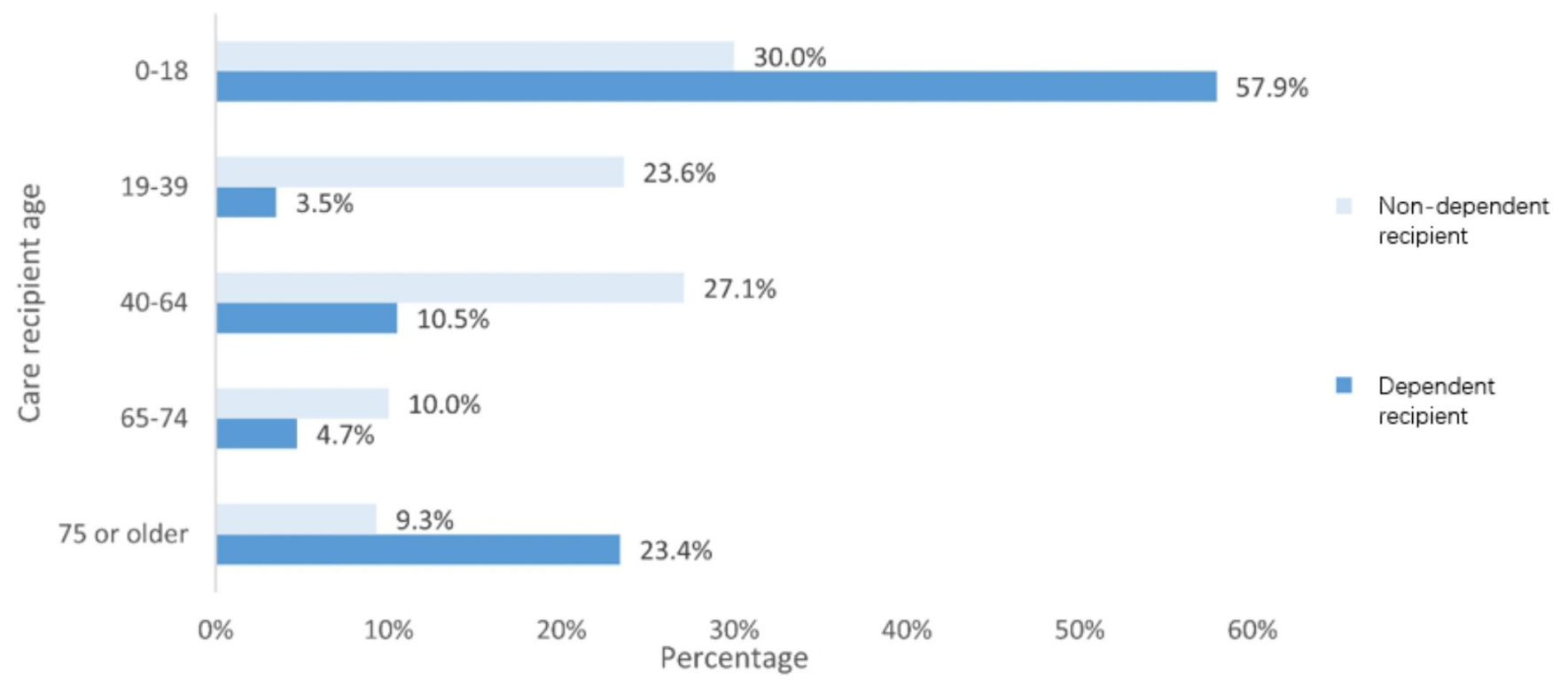

Fig. $1 b$

Figure 1 (A) Characteristics of care provider-recipient relationship among all care recipients, as reported by informal care providers ( $n=345)$. (B) Age distribution of dependent care receiver (who cannot live normally without caregivers' help). 
accounted for $17.8 \%$ (figure 1A). As cited by the informal care providers, the main reasons for recipients' need of home care was due to extreme age $(24.2 \%)$, had to stay at home due to COVID-19 epidemic (23.5\%), recipient's chronic medical conditions $(8.0 \%)$ and physical activities limitation $(4.3 \%)$. Over half $(533.8 \%)$ of home care recipients in the sample were considered as completely care dependent during the epidemic. Figure 1B showed most of the dependent care recipient were aged 0-18 years and aged 75 years or above $\left(\chi^{2} p\right.$ value: $\left.p<0.001\right)$. Gender difference was not significant between dependent and non-dependent care recipient.

\section{Who were the informal care provider during the COVID-19 pandemic? ( $\mathrm{n}=192)$}

In our study sample, one-quarter of respondents reported to have undertaken care responsibilities during the COVID-19 epidemic (table 1). Notably, about $83.7 \%$ of informal home care providers were the primary home care providers and informal home care providers were predominantly female $(67 \%, 129 / 192)$. Of informal home care providers, $44.8 \%$ were middle aged (45-64 years), 38\% were (73/192) aged $18-44$ years and $17.2 \%$ were aged 65 years or above. Although full-time housewives represented nearly one-quarter of the informal care providers, while $13.4 \%$ were unemployed or retired, more than $50 \%$ of informal home care providers were concurrently employed ( $44 \%$ were white collar employees). Multivariable logistic regression results indicated that younger adults, females, married people and housewives were more likely to be informal home care providers during the COVID-19 pandemic (table 1).

During this COVID-19 epidemic, nearly one in five of informal home care providers reported that they had to take personal leave from work or school to take care of their families. Informal home care providers who had taken personal leave were significantly more likely to be younger age (18-44 years of age) and were significantly more likely to have two or more dependent care recipients at home $\left(\chi^{2}\right.$ p value: $\left.<0.05\right)$. Meanwhiles, care provider's underlying chronic disease status, education attainment, housing types and household income were not statistically significant with informal home care responsibilities.

The association between income levels and informal home care duties was statistically insignificant $\left(\chi^{2} p\right.$ value: $>0.05)$. Yet, analysis showed home care providers from lower income subgroups (HKD 8000-19 999) tended to have to be responsible for more than one care recipient when compared with the higher income counterparts (figure 2). In addition, female was found to be the predominant gender to have taken up the primary informal care provider's role $\left(73.4 \%, \chi^{2}\right.$ p value: $\left.<0.001\right)$.

More than half of the informal home care providers were responsible for caring for more than one individual with nearly $20 \%(36 / 192)$ of respondents reporting that they needed to provide care to three or more household members. Of note, $64.7 \%$ of care providers reported that there was at least one dependent care recipient under their caring duties; $32.3 \%$ and $47.6 \%$ of care providers reported to be giving care to elderly family members (aged 65 years or above) and children under the age of 18 years or younger, respectively. Moreover, nearly $28 \%$ of households providing informal home care for fragile elderly, while $7.4 \%$ had people with disabilities.

A statistically significant age association was found between care provider and recipient. Elderly care providers were more likely to provide home care to those 65 years or older $(\mathrm{p}<0.05)$, while younger age (aged 18-44) tended to provide care for aged 18 years or younger care recipient $(\mathrm{p}<0.05))$. Younger care providers (aged 18-44 years) were more likely to provide home care to two or more dependent care recipient $(31.4 \%)$ than the older age group (age $45-64$ years: $21.0 \%$, age 65 years or above: $12.1 \%$, p value: 0.018 ). Meanwhile, other sociodemographic factor like gender, education attainment and housing of the care provider were not statistically significant. About $11.9 \%$ of care providers reported they had family members requiring care mainly due to their chronic disease condition. Non-married care providers (26.7\%; married: $7.1 \%$ ) were more likely to provide care for household members with chronic disease $(p<0.001)$.

\section{Physical, mental and social health of informal care providers during the COVID-19 pandemic}

Among the informal care providers, nearly 22\% reported having an underlying chronic medical condition themselves, but this proportion did not significantly differ from the non-informal care providers $(17.3 \%)$ (table 1 ). The perception of COVID-19's impact between provider and non-care provider is shown in table 2. Those providing informal home care showed no significant differences in self-reported impacts on physical health, social life and financial status, while significant difference was found for self-report impact of mental health status when compared between people with and without home care duties.

Notably, 53.9\% reported that they had experienced additional strain in their care providers' duties. The most commonly cited reasons for additional strains included COVID-19 health risk concern $(40.2 \%)$, increased time spent with care recipient $(27.5 \%)$ and more things need to take care of during the pandemic $(21.6 \%)$. For changes of community services (eg, day care centre) utilisation that facilitated pre-COVID-19 care, 41 subjects reported to have used community services regularly and among them $39 \%$ had stopped or decreased the use of the services due to the epidemic.

Of the informal home care providers, $37.2 \%$ reported that their daily lives became more challenging due to care duties for their family during COVID-19 epidemic. Multivariable regression analysis, however, showed that these perceptions were not associated with age, sex and education attainment nor the number of care recipient. However, providers who were having a dependent care recipient(s), and individuals having to take personal leave reported significantly increased difficulty in daily living $(\mathrm{p}<0.001)$ (see online supplemental table 1$)$. 
Table 1 Factors associated with having informal home care responsibilities during the COVID-19 pandemic in Hong Kong $(\mathrm{N}=765)$

\begin{tabular}{|c|c|c|c|c|c|}
\hline $\mathbf{N}$ & $\begin{array}{l}\text { Non-care provider } \\
(n=573)(\%)\end{array}$ & $\begin{array}{l}\text { Care provider } \\
(n=192)(\%)\end{array}$ & $\mathbf{P}$ & AOR $(95 \% \mathrm{Cl})$ & $P$ value \\
\hline Age (years) & & & $<0.001^{*}$ & & \\
\hline 18-24 & 12.0 & 1.0 & & Ref. & \\
\hline $25-44$ & 30.9 & 37.0 & & 5.34 (1.01 to 28.37 ) & $0.049^{*}$ \\
\hline $45-64$ & 37.9 & 44.8 & & 4.09 (0.76 to 22.14$)$ & 0.102 \\
\hline 65 or more & 19.2 & 17.2 & & 3.63 (0.63 to 20.85) & 0.148 \\
\hline Gender & & & $<0.001^{*}$ & & \\
\hline Male & 51.1 & 32.8 & & Ref. & \\
\hline Female & 48.9 & 67.2 & & 1.90 (1.29 to 2.82) & $0.001^{*}$ \\
\hline Education attainment & & & 0.125 & & \\
\hline Primary level or below & 8.1 & 7.8 & & & \\
\hline Secondary level & 41.2 & 49.5 & & & \\
\hline Tertiary level & 50.7 & 42.7 & & & \\
\hline Housing & & & 0.370 & & \\
\hline Public housing & 28.4 & 24.5 & & & \\
\hline Subsidised housing & 14.9 & 12.0 & & & \\
\hline Private housing & 55.3 & 62.5 & & & \\
\hline Others & 1.4 & 1.0 & & & \\
\hline Housing size & & & 0.499 & & \\
\hline Small (350 ft or below) & 22.1 & 18.4 & & & \\
\hline Medium (351-800 ft) & 63.0 & 67.6 & & & \\
\hline Large (801 ft or above) & 15.0 & 14.0 & & & \\
\hline Chronic disease & & & 0.155 & & \\
\hline No & 82.7 & 78.1 & & & \\
\hline Yes & 17.3 & 21.9 & & & \\
\hline Marital status & & & $<0.001^{*}$ & & \\
\hline Currently unmarried & 44.8 & 25.0 & & Ref. & \\
\hline Currently married & 55.2 & 75.0 & & 2.20 (1.45 to 3.35$)$ & $<0.001^{*}$ \\
\hline Employment & & & $<0.001^{*}$ & & \\
\hline White collar & 45.5 & 44.4 & & Ref. & \\
\hline Blue collar & 16.4 & 18.7 & & 1.43 (0.88 to 2.32$)$ & 0.144 \\
\hline Housewives & 8.8 & 23.0 & & 1.89 (1.08 to 3.31$)$ & $0.026^{*}$ \\
\hline Students & 8.1 & 0.5 & & 0.38 (0.04 to 3.88$)$ & 0.412 \\
\hline Unemployed and retired & 21.2 & 13.4 & & 0.80 (0.43 to 1.50$)$ & 0.488 \\
\hline Household income & & & 0.335 & & \\
\hline$<7999$ & 10.0 & 6.7 & & & \\
\hline 8000-19999 & 14.5 & 12.8 & & & \\
\hline 20 000-39 999 & 25.2 & 30.7 & & & \\
\hline 40000 or more & 50.3 & 49.7 & & & \\
\hline
\end{tabular}

In the multivariable logistic regression, there were two missing values in marital status and 11 missing values in employment. ${ }^{*} \mathrm{P}<0.05$.

Care provider's perceived knowledge sufficiency

While nearly $90 \%$ of these home care providers believed that they had sufficient knowledge to provide routine care, only $50.5 \%$ believed that they had sufficient knowledge to manage the additional risk brought on by COVID-19 (see online supplemental table 2). Although 


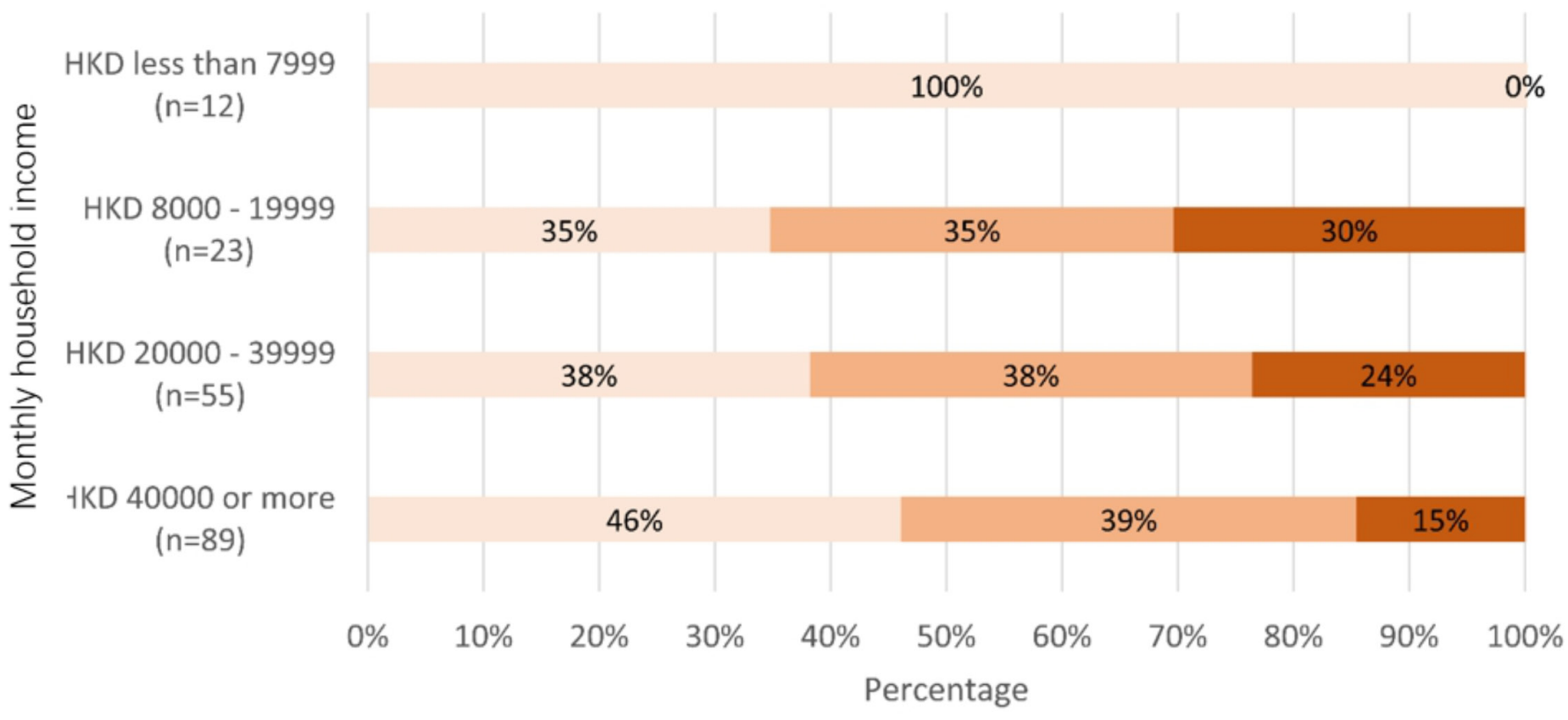

1 recipient $\square 2$ recipients $\square 3$ or more recipients

Figure 2 The relationship between household income and informal home care duties.

*There are 13 missing values in household income.

various sociodemographic factors and care recipient characteristics were associated with care providers' perceived adequacy of knowledge for providing routine home care, there was no statistically significant difference for perceived adequacy of knowledge in COVID-19 risk mitigation by any sociodemographic or care recipient factors.

\section{Home environment to facilitate home care and household COVID-19 risk control}

Among the study population $(\mathrm{n}=765)$, only 32 subjects $(4.2 \%)$ reported to have undergone home quarantine/isolation during the COVID-19 epidemic. Among these subgroups, $23(71.9 \%)$ took voluntary-based/selfimposed home isolation, while $9(28.1 \%)$ had to be home bound due to government compulsory home isolation requirements. Reasons cited for quarantine are due to recent travel abroad $(41.9 \%)$ and in close contacts with confirmed patients $(19.4 \%)$. Among the care providers, about $3.6 \%(7 / 192)$ reported that they had applied quarantine. Subjects were also asked about their preparation adequacy for potential home quarantine for 2 weeks. More than half of the subjects reported they had sufficient masks, detergent, disposable gloves and sufficient independent rooms for isolation use. For the general household preparation, more than $80 \%$ of participants have prepared alcohol rub, sufficient medicine and food and storage after COVID-19 epidemic started (table 3).

Respondents reported awareness and knowledge of home quarantine instructions. Most of them agreed that family members living with quarantined patients should check their temperature daily $(97.5 \%)$ and the quarantined subject should wear masks at home all the time $(96.1 \%)$. However, only half of the subjects $(51.3 \%)$ were able to answer that the ideal number of care providers for the person who is ill with COVID-19 should be only one.

Table 2 Differences in perception between care provider and non-care provider

\begin{tabular}{|c|c|c|c|}
\hline & $\begin{array}{l}\text { Non-care provider } \\
(\mathrm{N}=573)(\%)\end{array}$ & $\begin{array}{l}\text { Care provider } \\
(\mathrm{N}=192)(\%)\end{array}$ & P value \\
\hline \multicolumn{4}{|c|}{ Self-reported COVID-19 impact on physical, mental and social well-being } \\
\hline Believed COVID-19 had large effect on their mental health & 44.5 & 53.6 & $0.028^{*}$ \\
\hline Believed COVID-19 had large effect on their social life & 70.7 & 76.0 & 0.152 \\
\hline
\end{tabular}

${ }^{*} \mathrm{P}<0.05$. 
Table 3 Self-reported household items for COVID-19 control during the epidemic $(\mathrm{N}=765)$

\begin{tabular}{|c|c|}
\hline & $\mathbf{N}(\%)$ \\
\hline \multicolumn{2}{|l|}{ Household preparation items for potential quarantine } \\
\hline Masks & 86.8 \\
\hline Detergent & 92.9 \\
\hline Disposable gloves & 51.9 \\
\hline Sufficient independent room for isolation use & 65.2 \\
\hline \multicolumn{2}{|l|}{ General household preparation items } \\
\hline Alcohol rub & 95.2 \\
\hline Basic medicine (for fevers and common cold) & 92.4 \\
\hline Food and water storage sufficient for 1 day & 87.2 \\
\hline $\begin{array}{l}\text { Chronic disease medication enough for } 1 \text { week } \\
(n=241)\end{array}$ & 90.9 \\
\hline
\end{tabular}

About $70 \%$ and $26 \%$ answered the ideal ratio of bleach solution for cleaning were 1:99 and 1:49, respectively. As to the ideal distance with the quarantine subject in the same room, $324(42.4 \%)$ and $264(34.6 \%)$ of subjects answered $2 \mathrm{~m}$ and $1 \mathrm{~m}$, respectively.

\section{DISCUSSION}

During large-scale public health emergencies, home care may be the only viable method of providing continuous healthcare due to disruption of services and transportation. In many regions around the world, healthcare systems have been overwhelmed by high caseloads of COVID-19 patients with life-threatening conditions, necessitating greater reliance on informal home care providers. Home care providers during the COVID-19 pandemic include people caring for those with confirmed or suspected COVID-19 and caring for people with non-COVID-related conditions (eg, the health maintaining support and essential life sustaining care) and people bearing usual care responsibility for their family members. This is the first study to examine informal home care provision in highincome, urban context during a large-scale public health emergency. In our general population study sample of Hong Kong adults, approximately one-fourth reported to have provided informal home care during COVID-19 epidemic. About 20\% among the caregivers reported that they have to provide care to three or more care recipients during the pandemic. In Hong Kong, many of the adults will live with their parents and children in the same household. Hence, the adult tended to have to take care of their parents and children. Consistent with previous literature, ${ }^{8}$ females shouldered the main burden of being a primary home care provider. The COVID-19 pandemic presents a complex set of additional burdens on these home care providers. More than half of the informal home care providers reported additional mental strain during the epidemic.

Although the majority of informal home care providers believed that they had sufficient knowledge for their normal home care duties, we noted that some subgroups felt themselves to be insufficiently knowledgeable to provide even routine care. Previous studies have shown that older age and less educated care providers reported a higher mental burden from caregiving. ${ }^{25}{ }^{26}$ Consistent with this, we noted home care providers who were older, housewives and with lower education and income were more likely to believe themselves as lacking knowledge to provide routine care. Moreover, those caring for dependent individuals (eg, the elderly and the disabled) felt inadequately knowledgeable, possibly due to heavy reliance on existing services for regular management of frail elderly and people with disabilities by the government. ${ }^{27}$ In contrast to the provision of routine informal home care, nearly half of the informal home care providers reported that they had insufficient knowledge to mitigate the additional health risks from the COVID-19 epidemic and these findings were not associated with education or other factors.

On top of the additional economic and knowledge burden brought on by the worldwide pandemic, approximately half of the care providers reported additional mental strain during the epidemic. The most common reasons cited were the concerns of risk of COVID-19 infection in family, the longer duration of providing care and the additional caregiving tasks brought about from the pandemic. Nearly $40 \%$ of informal care providers reported that their caregiving duties had also caused increased difficulty in their daily life. Those reporting higher mental burden were often caring for dependent family members, and necessitating taking personal leave for the caregiving duties. Due to the COVID-19 pandemic, many community services like social community centre, ${ }^{28}$ day care centre ${ }^{12}$ and school ${ }^{29}$ were closed in Hong Kong. Hence, these home care providers with dependent care recipients require additional support services during public health emergencies. Furthermore, more than half of the care recipients were children and teenagers, who added to the caregiving burden during the nearly 4-month, territory-wide school closures. The closure of schools and elderly services has curtailed health access during the epidemic with $40 \%$ of the care providers reporting to have ceased or reduced using those services. In addition, it was found that the caregiving burden was highest in the economically active age group (aged 18-44 years). These individuals were often faced with a double burden of working and providing informal home care. Although government had subsidised the wages to employees, ${ }^{30}$ further support should target this care provider group. For example, providing sufficient information and services in internet or smartphone app, as younger aged care provider was found to be using more internet and smartphone app as their main information source comparing to other aged group. ${ }^{17}$

There were a few limitations in this study. Firstly, the study recruitment relied on land-based telephone. Households without land-based telephone services would be missed. However, the penetration rate of the 
residential fixed line services in Hong Kong was $85.5 \%$ in December $2019 .{ }^{31}$ In addition, our study population was comparable with the latest population Census in Hong Kong, which was generalisable to the general population. Furthermore, the study was conducted during the peak period of COVID-19 epidemic in Hong Kong. Citizens were encouraged to stay at home for work or daily activity. Hence, the respondents would be more compliant and attentive to the telephone survey. ${ }^{32}$ Second, the crosssectional study design can only demonstrate associations between patterns and social demographic predictors, as causation cannot be attributed to the findings. Third, this study might be subject to reporting bias since data were self-reported, and data from non-respondents could not be obtained. Fourth, our study did not further investigate the burdens, coping method and their perceived wellbeing of the care provider, which were potentially associated with the perceived difficulty of care giving. Lastly, the sample size of the subjects who perceived lacking knowledge to provide routine care was small $(n=20)$. Hence, advanced statistical analysis was not possible. Qualitative interviews might have revealed more rich and detailed insights.

Although the SARS-CoV-2/COVID-19 pandemic has engendered a huge amount of clinical, epidemiological and vaccine-related research, the socioeconomic impact of COVID-19 has not yet been well-examined. Home care, being one of the crucial pillars in supporting people's health outside the formal healthcare setting during this pandemic, needs much stronger research and support from stakeholders atvarious levels. ${ }^{33}$ In addition to research in formal healthcare services, better understanding of the challenges posed by the various home care settings (even informal settlements) is urgently required. This includes disease management in home care settings and strategies to optimise resources and support for informal care providers during global pandemics such as COVID19. This study examined informal home care providers in a high-income Asian city during the early phase of the pandemic. However, the long-term implications on care providers, health outcomes of care recipients and coping strategies of vulnerable people (particularly those living alone) are largely unknown. Research in these areas is urgently needed to improve pandemic preparedness of national health systems.

\section{CONCLUSION}

This study explores home care situation in Hong Kong, an Asian metropolis in China that experienced the early phase of COVID-19 in 2020. Findings showed home care during pandemic can present a complex set of care recipient needs and providers' duties in densely high-rise building based ageing community with a high dependency ratio. The study also showed that younger workers with higher education and income had to bear the main burden of care for dependent care recipients during the epidemic, but the heaviest routine care burden fell on those with deficit resource. Governments should consider supplementing service support during large-scale public health emergencies when access to routine healthcare is disrupted. Policy should focus on continuous support to those informal care providers and their mental health needs during these public health emergencies.

\section{Author affiliations}

${ }^{1}$ Collaborating Centre for Oxford University and CUHK for Disaster and Medical Humanitarian Response (CCOUC), The Chinese University of Hong Kong, Hong Kong, China

${ }^{2}$ Nuffield Department of Medicine, University of Oxford, Oxford, UK

${ }^{3} \mathrm{JC}$ School of Public Health and Primary Care, The Chinese University of Hong Kong, Hong Kong, China

${ }^{4}$ Accident \& Emergency Medicine Academic Unit, The Chinese University of Hong Kong, Prince of Wales Hospital, Hong Kong, China

${ }^{5}$ Nuffield Department of Primary Care Health Sciences, University of Oxford, Oxford, UK

Contributors EYYC, KKCH, ELYW, SYSW and NG conceived the project. EYYC, EL, $\mathrm{KKCH}$ and $\mathrm{ZH}$ designed the study tool, obtained, validated and cleaned the data. EL, $\mathrm{ZH}$ and JHK performed the data analysis. EYYC, ELYW, EL, JHK, HH and ZH involved in literature review and write up. All authors contributed to the manuscript drafting, review, revision and approval of the final manuscript. KKCH, EL, HH, SYSW and ZH provided administrative and operational support. The corresponding author attests that all listed authors meet authorship criteria and that no others meeting the criteria have been omitted.

\section{Funding}

This work was supported by Collaborating Centre for Oxford University and CUHK for Disaster and Medical Humanitarian Response (CCOUC)-0xford research support fund (\#0008).

Competing interests None declared.

Patient consent for publication Not required.

Ethics approval Verbal consent was obtained from the participant and ethics approval and consent procedure of the study was reviewed and obtained from the Survey and Behavioral Research Ethics Committee at The Chinese University of Hong Kong (SBRE-19-498).

Provenance and peer review Not commissioned; externally peer reviewed.

Data availability statement All data relevant to the study are included in the article. No additional data are available.

Supplemental material This content has been supplied by the author(s). It has not been vetted by BMJ Publishing Group Limited (BMJ) and may not have been peer-reviewed. Any opinions or recommendations discussed are solely those of the author(s) and are not endorsed by BMJ. BMJ disclaims all liability and responsibility arising from any reliance placed on the content. Where the content includes any translated material, BMJ does not warrant the accuracy and reliability of the translations (including but not limited to local regulations, clinical guidelines, terminology, drug names and drug dosages), and is not responsible for any error and/or omissions arising from translation and adaptation or otherwise.

Open access This is an open access article distributed in accordance with the Creative Commons Attribution Non Commercial (CC BY-NC 4.0) license, which permits others to distribute, remix, adapt, build upon this work non-commercially, and license their derivative works on different terms, provided the original work is properly cited, appropriate credit is given, any changes made indicated, and the use is non-commercial. See: http://creativecommons.org/licenses/by-nc/4.0/.

\section{ORCID iDs}

Eugene SK Lo http://orcid.org/0000-0001-9983-6219

Zhe Huang http://orcid.org/0000-0002-7922-0967

Kevin KC Hung http://orcid.org/0000-0001-8706-7758

Eliza LY Wong http://orcid.org/0000-0001-9983-6219 


\section{REFERENCES}

1 World Health Organization. Home care for patients with COVID-19 presenting with mild symptoms and management of their contacts: interim guidance. Geneva: WHO, 2020.

2 World Health Organization. Home-based and long-term care: home care issues and evidence. Geneva: WHO, 1999. https://apps.who. int/iris/bitstream/handle/10665/66096/WHO_HSC_LTH_99.2.pdf? sequence $=1$ \&isAllowed $=y$

3 Li J, Song Y. Formal and informal care. In: Gu D, Dupre ME, eds. Encyclopedia of gerontology and population aging. Cham: Springer International Publishing, 2019: 1-8.

4 Dow J, Robinson J, Robalino S, et al. How best to assess quality of life in informal carers of people with dementia; a systematic review of existing outcome measures. PLoS One 2018;13:e0193398.

5 Amer Nordin A, Mohd Hairi F, Choo WY, et al. Care recipient multimorbidity and health impacts on informal caregivers: a systematic review. Gerontologist 2019;59:e611-28.

6 Johnson S, Bacsu J, Abeykoon H, et al. No place like home: a systematic review of home care for older adults in Canada. Can J Aging 2018;37:400-19.

7 Lou WV. Financial impacts of family caregiving: an investigation of the moderating effects of workplace accommodative measures and domestic helpers, 2017. Available: https://www.pico.gov.hk/doc/en/ research_report(PDF)/2015_A8_031_16A_Final_Report_Dr_Lou.pdf

8 Ying S, Suzanne HO C, Alfred C-ming, et al. A study of informal caregivers and the association of caregiving status with health and quality of life. Hong Kong Med J 2007;13:S4-7.

9 Stein RA. COVID-19 and rationally layered social distancing. Int J Clin Pract 2020;74:e13501.

10 Wilder-Smith A, Chiew CJ, Lee VJ. Can we contain the COVID-19 outbreak with the same measures as for SARS? Lancet Infect Dis 2020;20:e102-7.

11 Education Bureau of the government of Hong Kong Special Administration. Deferral of class resumption for all schools together, we fight the virus, 2020. Available: https://www.edb.gov.hk/ attachment/en/sch-admin/admin/about-sch/diseases-prevention/ edb_20200331_eng.pdf

12 Government of the Hong Kong Special Administrative Region. LNY welfare services set, 2020. Available: https://www.news.gov.hk/eng/ 2020/01/20200127/20200127233955_845.html

13 New.gov.hk. Quarantine measures enhanced, 2020. Available: https://www.news.gov.hk/eng/2020/03/20200317/20200317_ 202509_713.html

14 Centre for Health Protection of the Government of Hong Kong Special Administrative Region. List of buildings of the confinees under mandatory quarantine according to cap. 599C of Hong Kong laws, 2020. Available: https://www.chp.gov.hk/files/pdf/599c_tc.pdf

15 Chan EYY, Gobat N, Kim JH, et al. Informal home care providers: the forgotten health-care workers during the COVID-19 pandemic. Lancet 2020;395:1957-9.

16 Census and Statistics Department of Government of Hong Kong Special Administrative Region. Domestic households in Hong Kong, 2016. Available: https://www.bycensus2016.gov.hk/en/Snapshot-04. html

17 Chan EYY, Huang Z, Lo ESK, et al. Sociodemographic predictors of health risk perception, attitude and behavior practices associated with health-emergency disaster risk management for biological hazards: the case of COVID-19 pandemic in Hong Kong, SAR China. Int J Environ Res Public Health 2020;17:3869.

18 Chan EY-Y, Cheng CK-Y, Tam GC-H, et al. Willingness of future AV H7N9 influenza vaccine uptake: a cross-sectional study of Hong Kong community. Vaccine 2015;33:4737-40.

19 Chan EYY, Cheng CKY, Tam G, et al. Knowledge, attitudes, and practices of Hong Kong population towards human A/H7N9 influenza pandemic preparedness, China, 2014. BMC Public Health 2015;15:943.

20 Tam G, Huang Z, Chan E. Household preparedness and preferred communication channels in public health emergencies: a crosssectional survey of residents in an Asian developed urban City. Int J Environ Res Public Health 2018;15:1598.

21 Chan YYE, Wong CS. Public health prevention hierarchy in disaster context. In: Chan YYE, Shaw R, eds. Public health and disasters - health emergency and disaster risk management in Asia. Tokyo: Springer, 2020: 7-17.

22 Centre for Health Protection of the government of Hong Kong Special Administrative Region. Communicable diseases, 2020. Available: https://www.chp.gov.hk/en/resources/464/102466.html

23 Census and Statistics Department of the Government of the Hong Kong Special Administrative Region. Main Table (By-Census Results) [Internet]. [cited 2019 Oct 31]. Available: https://www.bycensus2016. gov.hk/en/bc-mt.html

24 IBM. SPSS statistics 21.0 available for download, 2020. Available: https://www.ibm.com/support/pages/spss-statistics-210-availabledownload

25 Oi-wah CE, Ho HCY. Caregiver strain, age, and psychological well-being of older spousal caregivers in Hong Kong. J Soc Work 2015;15:479-97.

26 Oedekoven M, Amin-Kotb K, Gellert P, et al. Associations between informal caregivers' burden and educational level. GeroPsych 2019;32:19-29.

27 Social Welfare Deparment. Integrated home care services, 2015. Available: https://www.swd.gov.hk/doc/elderly/lHCS (Nov 2015).pdf

28 Government of the Hong Kong Special Administrative Region. Public service arrangements updated, 2020. Available: https://www.news. gov.hk/eng/2020/03/20200322/20200322_131634_065.html?type= ticker

29 Government of the Hong Kong Special Administrative Region. No delay in fight against virus: Ce, 2020. Available: https://www.news. gov.hk/chi/2020/01/20200125/20200125_191553_178.html?type= category\&name=covid19\&tl=t

30 News.gov.hk. Gov't unveils employment measures, 2020. Available: https://www.news.gov.hk/eng/2020/04/20200420/20200420_ 175816_569.html

31 Office of the Communications Authority Key Communications Statistics of the government of Hong Kong Special Administrative Region. Key communications statistics, 2019. Available: https://www. ofca.gov.hk/en/data_statistics/data_statistics/key_stat/

32 Office of the Communications Authority. Key communications statistics, 2012. Available: https://www.ofca.gov.hk/en/data_ statistics/data_statistics/key_stat/

33 Chan EYY, Gobat N, Hung H, et al. Health-Emergency and Disaster Risk Management (Health-EDRM) technical brief series: a review on implications of home care in a biological hazard, 2020. Available: http://www.ccouc.ox.ac.uk/_asset/file/a-review-on-implications-ofhome-care-in-a-biological-hazard.pdf 